\title{
NYA RÖN OM BLADANALYSENS ANVÄNDNING
}

\author{
HJalmar Selenius \\ Alands försöksstation, Jomala
}

Mottaget 30.3. 1972

\author{
NEW EXPERIENCES IN THE USE OF LEAF ANALYSIS
}

Hjalmar Selentus

Experimental station of Aland, Jomala

\begin{abstract}
This study, which is part of a more extensive investigation in resistance to drought, has through special circumstances led to a method of obtaining through leaf analysis a proportion between nitrogen and potassium which is characteristic for every species and variety. This proportion depends on the colour of the leaf, graduated according to the shade of blue-green - yellow-green and dark - light, which again depends on whether chlorophyll a, blue-green, or chlorophyll b, yellow-green, is the dominant substance that gives its colour to the leaves.

The N/K proportion varies from about 3.20 in pine and juniper needles to about 1.00 in certain oats varieties. Analyses of samples from a combined nitrogen fertilizing and irrigation experiment with spring cereals, $1964-67$, showed that irrigation as well as nitrogen fertilizing constantly increased the $\mathrm{N} / \mathrm{K}$ proportion. In an experiment arranged in 1971 by spraying strawshortening substance (CCC, $4 \mathrm{~kg} / \mathrm{ha}$ ) on winter and spring wheat, oats and barley varieties, it was proved that this treatment, which generally brings about a changing of the colour of the leaves in the direction from yellow-green to blue-green also generates an increase in the $\mathrm{N} / \mathrm{K}$ proportion.
\end{abstract}

\section{Inledning}

De undersökningar, för vilka här redogöres, ingår egentligen i ett större sammanhang, nämligen frågan om torkresistensen och möjligheterna att påvisa denna. Förutsättningarna för dylika undersökningar är gynnsamma på Ålands försöksstation i Jomala, där vårarna och försomrarna är torrare än annorstädes i landet (Tabell 1).

Under de torra åren 1955-58 gav kornsorten Foma anmärkningsvärt höga skördar i förhållande till andra kornsorter. Men det var först under den torra våren 1963 som man tydligt lade märke till den blågröna färgen, klorofyll a:s färg, hos bladen av denna sort, vilken iakttagelse gav upphov till den här undersökningen.

Man har även i vissa fall kunnat märka en direkt skördestegrande effekt vid användningen av stråförkortningsmedlet CCC, tydligast, enligt erfarenheter i Sverige, där man mest lider av försommartorka, såsom på Gottland, Öland och i Östersjöns kusttrakter. Man kan även iakttaga, att användningen av CCC förändrar bladfärgen på de besprutade plantorna, så att de får en mera blågrön skiftning. 
Tabell 1. Väderleksförhållandena i Jomala 1963-71.

Table 1. Weather conditions at Jomala 1963-71.

\begin{tabular}{|c|c|c|c|c|c|c|c|c|c|c|c|}
\hline \multirow{4}{*}{$\begin{array}{l}\text { År } \\
\text { Year }\end{array}$} & \multirow{2}{*}{\multicolumn{4}{|c|}{$\begin{array}{l}\text { Medeltemperatur }{ }^{\circ} \mathrm{C} \\
\text { Mean temperature }{ }^{\circ} \mathrm{C}\end{array}$}} & \multirow{2}{*}{\multicolumn{4}{|c|}{$\begin{array}{l}\text { Nederbörd i mm } \\
\text { Precipitation } \mathrm{mm}\end{array}$}} & \multicolumn{3}{|c|}{ Såtid - Sowing date } \\
\hline & & & & & & & & & \multirow{3}{*}{$\begin{array}{c}\text { Vårvete } \\
\text { Spring } \\
\text { wheat }\end{array}$} & \multirow{3}{*}{$\begin{array}{l}\text { Korn } \\
\text { Barley }\end{array}$} & \multirow{3}{*}{$\begin{array}{c}\text { Havre } \\
\text { Oats }\end{array}$} \\
\hline & April & Maj & Juni & Juli & April & Maj & Juni & Juli & & & \\
\hline & April & May & June & fuly & April & May & Fune & fuly & & & \\
\hline 1963 & 1.2 & 10.1 & 13.4 & 15.9 & 38 & 16 & 24 & 26 & 9.5 . & 14.5. & \\
\hline 1964 & 2.4 & 8.7 & 12.8 & 15.4 & 18 & 9 & 34 & 33 & 9.5 . & 9.5. & \\
\hline 1965 & 3.4 & 6.1 & 12.8 & 14.0 & 18 & 9 & 10 & 104 & 7.5. & 7.5. & \\
\hline 1966 & -0.6 & 7.6 & 15.2 & 16.7 & 36 & 22 & 20 & 45 & 16.5. & 16.5. & \\
\hline 1967 & 3.1 & 7.3 & 12.4 & 16.3 & 29 & 60 & 37 & 21 & 11.5. & 11.5. & \\
\hline 1968 & 4.1 & 6.6 & 14.8 & 15.0 & 44 & 61 & 18 & 30 & 2.5 . & 29.4 . & \\
\hline 1969 & 2.9 & 7.4 & 14.5 & 16.2 & 23 & 42 & 3 & 47 & 13.5. & 19.5. & \\
\hline 1970 & 1.1 & 8.0 & 14.8 & 14.9 & 59 & 6 & 13 & 49 & 8. 5 . & 9. 5. & 8. 5 . \\
\hline 1971 & 1.8 & 8.7 & 12.8 & 16.3 & 32 & 9 & 29 & 53 & 22.4. & 22.4 & 23. 4 . \\
\hline Normal & 2.6 & 7.9 & 12.6 & 16.4 & 33 & 32 & 37 & 45 & & & \\
\hline
\end{tabular}

Enligt Halldahl (1966) är förhållandet mellan klorofyll a och b 3:1. Men klorofyll a i levande celler förekommer i olika former, som kan registreras spektrofotometriskt, och de olika klorofyllformerna har fått namn efter sina absorptionsmaxima i rött. I de flesta växter har det visat sig möjligt att urskilja tre former, $\mathrm{C}_{\mathrm{a}} 670, \mathrm{C}_{\mathrm{a}} 682$ och $\mathrm{C}_{\mathrm{a}} 700 . \mathrm{Om}$ klorofyllet extraheras, får man bara ut en typ, den som vi vanligtvis menar med klorofyll a, med ett rött absorptionsmaximum i eter vid våglängden $662 \mathrm{~nm}$. Det är troligtvis denna som åstadkommer den blågröna färgen hos bladen, ty om alla formerna skulle medverka, vore det omöjligt för klorofyll b att hos bladen hos endel växter få fram den gulgröna färgen eller klorofyll b:s färg. Dess absorptionsmaximum i rött är $660 \mathrm{~nm}$, således nästan detsamma som för den extraherade formen av klorofyll a. Det förefaller som om det tillsvidare inte skulle vara möjligt att med analys av klorofyll a och b få fram säkra uppgifter om deras verkliga förhållande till varandra.

Emedan koppar hör till de spårämnen, som det råder brist på Jomala, har man, där denna brist påvisats, tillfört kopparsulfat, $50 \mathrm{~kg} / \mathrm{ha}$, vilket resulterat $\mathrm{i}$ att bladen fått en mycket intensivare grön färg. Detta ledde till tanken, att man genom bladanalys skulle få tal som skulle motsvara halten av klorofyll a och b i bladen.

Bladanalysmetoden, som utvecklats av LUNDEGÅRDH (1954), går ut på att man tar bladprov vid blomningens början och de analyseras på halten av kväve, kalium och fosfor, varigenom man kan avläsa jordens förmåga att leverera dessa ämnen till växterna och den utgör därför en komplettering till den kemiska jordanalysen. PuUsTJÄRvi (1965) har använt barranalys av tallbarr på kväve, kalium och fosfor för att med tillhjälp av förhållandena $\mathrm{N} / \mathrm{K}$ och $\mathrm{N} / \mathrm{P}$ fastställa gödslingsbehovet på torvmarker av olika typ.

\section{Material och metoder}

Sommaren 1969 insändes prov av tallbarr som är klart blågröna och av granbarr som är mörkt gulgröna till torvforskningsinstitutet, Hyrylä, för att analyseras på kväve och 
kalium. Då man hos enen kan lägga märke till att barrens färg är beroende på växtplatsen, blågröna på torra platser och gulgröna på fuktigare och bördigare, togs sommaren 1970 prov av enris på dylika platser. Samtidigt togs prov av Drott vårvete och Foma korn med blågrön bladfärg, ävensom av Svenno vårvete och Balder korn med gulgröna blad. Proven insändes till torvforskningsinstitutet för analys av kväve och kalium. Det togs även prov av två andra kornsorter, Pomo och Karri, samt två havresorter, Sisu och Linda, som följande sommar analyserades på agrikulturkemiska laboratoriet i Vik. Kvävet bestämdes enligt Kjeldahl-metoden och kalium flamfotometriskt.

Vid provtagningen graderades bladfärgen med $1-2$ för gulgrön och $4-5$ för blågrön färg, samt som komplettering 1 för ljus och m för mörk färg.

Sommaren 1971 togs också prov av två växter, som något skiljer sig från varandra i fråga om bladfärgen, Aegopodium podagraria, kirskål och Saponaria officinalis, såpört. Därtill analyserades i laboratoriet i Vik bladprov av Cerastium tomentosum, silverarv.

År 1964 igångsattes i Jomala ett kombinerat bevattnings- och kvävegödslingsförsök i vårsäd omfattande 4 år. I detta ingick förutom Foma en annan kornsort, Balder med gulgröna blad samt två vårvetesorter, Svenno med gulgrön och Drott med blågrön bladfärg. Drott har även visat sig vara torkresistent, dock inte i lika hög grad som Foma. Bevattningen, två gånger $12 \mathrm{~mm}$, utfördes i mitten av juni och början av juli. Kvävegödselmängden var $300 \mathrm{~kg} \mathrm{~N} \mathrm{~N}_{\mathrm{ks}} / \mathrm{ha}$.

För de resultat man kommit till finnes redogjort i försöksberättelsen från Ålands försöksstation 1967. Här skall blott framhållas, att under de tre första, tämligen torra åren, torkresistensen hos Foma och Drott tämligen klart framträdde i rutorna utan bevattning och i desamma med kvävegödsling. Men Drott utnyttjade även bäst såväl bevattning som gödsling. Som komplettering till detta försök insåddes rutor på $0.75 \mathrm{~m}^{2}$ under plasttak av varje försöksled, från vilka sedan togs små prov från tiden efter broddskjutning till axgången med en veckas mellanrum. En del av dessa prov insändes till olika laboratorier för analys på halten av klorofyll a och b, men resultaten visade sig vara så varierande och otillförlitliga, att de inte kunde utnyttjas.

Då det fanns prov kvar från försöksrutorna under plasttak, tagna somrarna $1964-67$, analyserades endel prov på agrikulturkemiska laboratoriet i Vik sommaren 1971, för att få fram bevattningens och kvävegödslingens inverkan på N/K förhållandet. Tyvärr blev undersökningen inte så fullständig och tillförlitlig som hade varit önskvärt, beroende dels på att proven togs mycket för tidigt i vissa fall, dels på att somliga prov var för små att kunna användas.

För att undersöka huruvida CCC-besprutningen inverkar på N/K förhållandet igångsattes därför försök vid Ålands försöksstation sommaren 1971. Ena hälften av de skyddsrutor, som fanns vid ändarna av varje sortförsök, besprutades med CCC ( $4 \mathrm{~kg} / \mathrm{ha})$, medan andra hälften lämnades obesprutad. Besprutningen skedde i medlet av juni månad. Från dessa rutor togs sedan prov, vid tiden för blomningens början, och bladfärgen graderades. Proven analyserades i laboratoriet i Vik. Resultaten av två rutor måste kasseras, nämligen av Linna höstvete, där proven blev tagna alldeles för tidigt och av Kristina korn, där växtbeståndet till följd av angrepp av randiga jordloppan och bladlöss var alldeles för ojämnt. 
Tabell 2. Bladfärg och $\mathrm{N} / \mathrm{K}$ förhållandet hos ett antal typiska växtarter och -sorter.

Table 2. Leaf colour and $\mathcal{N} / K$ proportion in some typical species and varieties.

\begin{tabular}{|c|c|c|c|c|c|}
\hline $\begin{array}{l}\text { Art och sort } \\
\text { Species and variety }\end{array}$ & $\begin{array}{l}\text { Provtagn. } \\
\text { datum } \\
\text { Sampling date }\end{array}$ & $\begin{array}{l}\text { Bladfärg* } \\
\text { Leaf colour* }\end{array}$ & $\begin{array}{l}\mathrm{N} \\
\%\end{array}$ & $\begin{array}{l}\mathrm{K} \\
\%\end{array}$ & $\mathrm{~N} / \mathrm{K}$ \\
\hline Pinus silvestris & 15. 7. 1969 & 5 & 1.28 & 0.40 & 3.20 \\
\hline Picea exelsa & $"$ & m 1 & 1.05 & 0.76 & 1.38 \\
\hline Juniperus communis & 17. 7.1970 & & & & \\
\hline torr jord $-d r y$ soil & & 4.5 & 1.19 & 0.37 & 3.22 \\
\hline fuktig jord - moist soil & & 2 & 0.91 & 0.42 & 2.17 \\
\hline Vårvete - Spring wheat & 10. 7.1970 & & & & \\
\hline Svenno & & 12 & 2.20 & 1.72 & 1.28 \\
\hline Drott & & 4 & 2.87 & 1.79 & 1.60 \\
\hline Korn - Barley & 10. 7.1970 & & & & \\
\hline Foma & & 4.5 & 3.50 & 2.64 & 1.32 \\
\hline Balder & & 2 & 3.79 & 2.97 & 1.28 \\
\hline Karri & & 3.5 & 3.06 & 2.53 & 1.21 \\
\hline Pomo & & 2 & 3.03 & 2.92 & 1.04 \\
\hline Havre - Oats & 10. 7.1970 & & & & \\
\hline Sisu & & 14 & 3.51 & 3.43 & 1.02 \\
\hline Linda & & 12.5 & 2.10 & 3.50 & 0.60 \\
\hline Aegopodium podagraria & 28. 6.1971 & 2.5 & 3.30 & 2.00 & 1.65 \\
\hline Cerastium tomentosum & $"$ & $12(4.5)$ & 2.49 & 2.40 & 1.04 \\
\hline Saponaria officinalis & 20.8.1971 & 4 & 3.33 & 1.87 & 1.78 \\
\hline
\end{tabular}

* Bladfärg och dess intensitet: $1-2=$ gulgrön, $4-5=$ blågrön; $1=$ ljus, $\mathrm{m}=$ mörk.

* Leaf colour and its intensity: $1-2=$ yellow-green, $4-5=$ blue-green; $l=$ light,$m=$ dark.

\section{Resultat och diskussion}

Bladanalysens användning för att påvisa N/K förhållan$\mathrm{dets}$ beroende av bladfä rgen. Det framgår av Tabell 2, att det rådde en väsentlig skillnad i N/K förhållandet för tallbarr, 3.20, och för granbarr, 1.38. Proven var tagna från samma mark, alldeles intill varandra, men tallbarr var klart blågröna och granbarr mörkt gulgröna.

Analyserna av enens barr överensstämmer med de av tall- och granbarr. Sålunda gav analysen av enbarr från torr plats $\mathrm{N} / \mathrm{K}$ förhållandet 3.22 och från fuktig plats 2.17. För vårvete-sorterna är skillnaderna mindre, 1.60 och 1.22, men de är i alla fall i rätt riktning. Att skillnaderna för kornet inte blivit större, måste bero på att proven inte blivit tagna vid den absolut rätta tidpunkten vid blomningens början. För Karri, Pomo och Sisu överensstämmer deras $\mathrm{N} / \mathrm{K}$ förhållande tämligen väl med bladfärgen. Att detta för Linda blev så lågt torde bero på att provet togs något för tidigt $\mathrm{i}$ förhållande till blomningen.

N/K förhållandet för kirskål var 1.65 och för såpört 1.78. Ett intressant fall utgör silverarv, vars bladfärg graderades $14.5=$ ljust blågrön, men som egentligen seglade under 
Tabell 3. N/K förhållandet från det kombinerade kvävegödslings- och bevattningsförsöket $\mathrm{i}$ vårsäd $1964-67$.

Table 3. $\mathcal{N} / K$ proportion in samples of the combined nitrogen fertilization and irrigation experiment with spring cereals $1964-1967$.

$$
\begin{aligned}
\mathrm{I} & =\text { obevattnad }- \text { not irrigated } \\
\mathrm{II} & =\text { bevattnad }- \text { irrigated } 2 \times 12 \mathrm{~mm} \\
\mathrm{a} & =\text { ogödslad }- \text { not fertilized } \\
\mathrm{b} & =\text { gödslad med } \mathrm{N}_{\mathrm{ks}}-\text { fertilized with calcium nitrate } 300 \mathrm{~kg} / \mathrm{ha}
\end{aligned}
$$

\begin{tabular}{|c|c|c|c|c|c|c|c|c|c|c|}
\hline $\begin{array}{l}\text { Art och sort } \\
\text { Species and variety }\end{array}$ & & & $\begin{array}{l}\text { Provtagn. } \\
\text { datum } \\
\text { Sampling } \\
\text { date }\end{array}$ & $\begin{array}{l}\text { Blad- } \\
\text { färg** } \\
\text { Leaf } \\
\text { colour* }\end{array}$ & $\begin{array}{l}\mathrm{N} \\
\%\end{array}$ & $\begin{array}{l}\mathrm{K} \\
\%\end{array}$ & $\mathrm{~N} / \mathrm{K}$ & $\begin{array}{c}\text { Medel } \\
\text { Sort } \\
\text { Variety }\end{array}$ & $\begin{array}{l}\text { Als }-\mathrm{Mec} \\
\text { Bevattn. } \\
\text { Irrig. }\end{array}$ & $\begin{array}{l}\text { ns } / \mathrm{K} \\
\text { Gödsl. } \\
\text { Fertil. }\end{array}$ \\
\hline Vårvete - Spring wheat & $\begin{array}{c}\text { Svenno } \\
" \\
" \\
" \\
\text { Drott } \\
" \\
" \\
"\end{array}$ & $\begin{aligned} \text { I } & \mathrm{a} \\
\text { I } & \mathrm{b} \\
\text { II } & \mathrm{a} \\
\text { II } & \mathrm{b} \\
\text { I } & \mathrm{a} \\
\text { I } & \mathrm{b} \\
\text { II } & \mathrm{a} \\
\text { II } & \mathrm{b}\end{aligned}$ & $\begin{array}{c}\text { 16. } 7.1964 \\
" \\
" \\
" \\
" \\
" \\
" \\
"\end{array}$ & $\begin{array}{l}2 \\
2 \\
2 \\
2 \\
4 \\
4 \\
4 \\
4\end{array}$ & $\begin{array}{l}2.95 \\
2.72 \\
3.14 \\
2.95 \\
2.81 \\
3.17 \\
3.65 \\
3.06\end{array}$ & $\begin{array}{l}3.00 \\
2.68 \\
2.45 \\
2.10 \\
2.60 \\
2.83 \\
2.20 \\
2.05\end{array}$ & $\begin{array}{l}0.98 \\
1.01 \\
1.34 \\
1.40 \\
1.08 \\
1.12 \\
1.66 \\
1.49\end{array}$ & 1.18 & $\begin{array}{rr}\text { I } & 1.00 \\
\text { II } & 1.37\end{array}$ & $\begin{array}{l}\text { a } 1.16 \\
\text { b } 1.21 \\
\\
\text { a } 1.37 \\
\text { b } 1.31\end{array}$ \\
\hline Korn - Barley & $\begin{array}{c}\text { Foma } \\
" \\
" \\
" \\
\text { Balder } \\
" \\
" \\
"\end{array}$ & $\begin{aligned} \text { I } & \mathrm{a} \\
\text { I } & \mathrm{b} \\
\text { II } & \mathrm{a} \\
\text { II } & \mathrm{b} \\
\text { I } & \mathrm{a} \\
\text { I } & \mathrm{b} \\
\text { II } & \mathrm{a} \\
\text { II } & \mathrm{b}\end{aligned}$ & $\begin{array}{l}" \\
" \\
" \\
" \\
" \\
" \\
" \\
"\end{array}$ & $\begin{array}{l}4.2 \\
4.2 \\
4.2 \\
4.2 \\
1.8 \\
1.8 \\
1.8 \\
1.8\end{array}$ & $\begin{array}{l}3.09 \\
2.64 \\
2.89 \\
2.92 \\
2.58 \\
2.03 \\
2.83 \\
2.97\end{array}$ & $\begin{array}{l}3.30 \\
2.83 \\
2.45 \\
2.57 \\
3.30 \\
2.92 \\
3.00 \\
3.25\end{array}$ & $\begin{array}{l}0.94 \\
0.93 \\
1.18 \\
1.14 \\
0.78 \\
0.70 \\
0.94 \\
0.91\end{array}$ & 1.05 & $\begin{array}{rr}\text { I } & 0.94 \\
\text { II } & 1.16 \\
& \\
\text { I } & 0.74 \\
\text { II } & 0.93\end{array}$ & $\begin{array}{ll}\text { a } & 1.06 \\
\text { b } & 1.04 \\
& \\
\text { a } & 0.86 \\
\text { b } & 0.81\end{array}$ \\
\hline Vårvete - Spring wheat & $\begin{array}{c}\text { Svenno } \\
\text { " } \\
\text { Drott } \\
"\end{array}$ & $\begin{array}{ll}\text { II } & \mathrm{a} \\
\text { II } & \mathrm{b} \\
\text { II } & \mathrm{a} \\
\text { II } & \mathrm{b}\end{array}$ & $\begin{array}{c}\text { 21. } 7.1965 \\
" n \\
" \\
"\end{array}$ & $\begin{array}{l}2 \\
2 \\
4 \\
4\end{array}$ & $\begin{array}{l}2.10 \\
1.76 \\
2.47 \\
1.99\end{array}$ & $\begin{array}{l}3.10 \\
3.10 \\
2.40 \\
2.43\end{array}$ & $\begin{array}{l}0.68 \\
0.57 \\
1.03 \\
0.82\end{array}$ & $\begin{array}{l}0.68 \\
0.93\end{array}$ & & \\
\hline Korn - Barley & $\begin{array}{c}\text { Foma } \\
\text { Balder } \\
\text { " }\end{array}$ & $\begin{array}{ll}\text { II } & \mathrm{a} \\
\text { II } & \mathrm{b} \\
\text { II } & \mathrm{a} \\
\text { II } & \mathrm{b}\end{array}$ & $\begin{array}{l}" \\
" \\
"\end{array}$ & $\begin{array}{l}4.2 \\
4.2 \\
1.8 \\
1.8\end{array}$ & $\begin{array}{l}2.30 \\
1.54 \\
1.60 \\
1.71\end{array}$ & $\begin{array}{l}2.43 \\
2.25 \\
2.36 \\
2.36\end{array}$ & $\begin{array}{l}0.95 \\
0.68 \\
0.68 \\
0.72\end{array}$ & $\begin{array}{l}0.82 \\
0.70\end{array}$ & & \\
\hline $\begin{array}{l}\text { Vårvete - Spring wheat } \\
\text { Korn - Barley }\end{array}$ & $\begin{array}{l}\text { Svenno } \\
\text { Drott } \\
\text { Foma } \\
\text { Balder }\end{array}$ & $\begin{array}{ll}\text { II } & \mathrm{a} \\
\text { II } & \mathrm{a} \\
\text { II } & \mathrm{a} \\
\text { II } & \mathrm{a}\end{array}$ & $\begin{array}{c}\text { 7. 7. } 1966 \\
" \\
" \\
"\end{array}$ & $\begin{array}{l}2 \\
4 \\
4.2 \\
1.8\end{array}$ & $\begin{array}{l}2.96 \\
2.80 \\
2.73 \\
2.73\end{array}$ & $\begin{array}{l}2.15 \\
2.29 \\
1.92 \\
2.63\end{array}$ & $\begin{array}{l}1.38 \\
1.22 \\
1.42 \\
1.04\end{array}$ & & & \\
\hline Vårvete - Spring wheat & $\begin{array}{c}\text { Svenno } \\
" \\
" \\
\text { Drott } \\
" \\
" \\
"\end{array}$ & $\begin{array}{rr}\text { I } & \mathrm{a} \\
\text { II } & \mathrm{a} \\
\text { II } & \mathrm{b} \\
\text { I } & \mathrm{a} \\
\text { II } & \mathrm{a} \\
\text { II } & \mathrm{b}\end{array}$ & $\begin{array}{l}\text { 8. 7. } 1967 \\
" \\
" \\
" \\
" \\
"\end{array}$ & $\begin{array}{l}2 \\
2 \\
2 \\
4 \\
4 \\
4\end{array}$ & $\begin{array}{l}1.51 \\
2.02 \\
1.94 \\
1.63 \\
2.13 \\
2.05\end{array}$ & $\begin{array}{l}3.43 \\
3.17 \\
3.54 \\
3.50 \\
3.85 \\
3.50\end{array}$ & $\begin{array}{l}0.44 \\
0.64 \\
0.55 \\
0.47 \\
0.55 \\
0.59\end{array}$ & $\begin{array}{l}0.54 \\
0.54\end{array}$ & & \\
\hline Korn - Barley & $\begin{array}{c}\text { Foma } \\
" \\
\text { Balder } \\
" \\
"\end{array}$ & $\begin{array}{rr}\text { I } & \mathrm{a} \\
\text { II } & \mathrm{a} \\
\text { II } & \mathrm{b} \\
\text { I } & \mathrm{a} \\
\text { II } & \mathrm{a} \\
\text { II } & \mathrm{b}\end{array}$ & $\begin{array}{l}" \\
" \\
" \\
" \\
"\end{array}$ & $\begin{array}{l}4.2 \\
4.2 \\
4.2 \\
1.8 \\
1.8 \\
1.8\end{array}$ & $\begin{array}{l}1.38 \\
1.99 \\
1.94 \\
1.05 \\
1.35 \\
1.38\end{array}$ & $\begin{array}{l}4.00 \\
3.60 \\
3.65 \\
4.40 \\
3.93 \\
3.58\end{array}$ & $\begin{array}{l}0.35 \\
0.55 \\
0.53 \\
0.24 \\
0.34 \\
0.39\end{array}$ & $\begin{array}{l}0.48 \\
0.32\end{array}$ & & \\
\hline
\end{tabular}

* Se Tabell 2.

* See Table 2. 
falsk flagg, ty då man för analysernas skull i en liten kvarn krossade bladen till pulver, blev detta klart gulgrönt och $\mathrm{N} / \mathrm{K}$ förhållandet blev även 1.04.

I enstaka fall kan sålunda $\mathrm{N} / \mathrm{K}$ vara ett annat än vad bladfärgen skulle förutsätta, men i själva verket är det klorofyllhalten som avgör. Denna undersökning skall kompletteras med andra växtarter och -sorter samt av en del av de tidigare undersökta växterna skall nya prov tagas med noggrannare iakttagande av blomningstiden.

Bevattningens och kvävegödslingens inverkan på N/K fö r h å 11 a n d e t. Granskar man Tabellen 3 från 1964 finner man först och främst, att förhållandet mellan sorterna ganska väl överensstämmer med detsamma i Tabell 2, ehuru talen är något lägre, som man ju kan vänta med beaktande av tiden för provtagningen, som dock var nära den idealiska för vårvetet. Bevattning har genomgående gett högre tal än obevattnat, medan N-gödsling för vårvetet gett högre tal, men för kornet obetydligt lägre än för ogödslat. Detta senare måste dock bero på för tidigt tagna prov.

Proven från följande år som hade en sval maj och juli togs alldeles för tidigt, varför talen blev mycket låga och otillförlitliga. Från år 1966 fanns det prov kvar endast från de obevattnade och ögodslade rutorna och då proven togs något för tidigt, är resultaten icke fullt tillförlitliga. Från år 1967 fanns det något flera prov kvar, men då dessa tagits förhållandevis ännu tidigare än under föregående år, gav analyserna låga och därigenom otillförlitliga tal. Dock är förhållandet mellan sorterna någorlunda normalt och bevattningen har gett högre tal än obevattnat samt gödslat något högre än ogödslat och överensstämmer med resultaten från 1964.

I stort sett har analyserna gett resultat, som ger någorlunda säkra svar på frågan om bevattningens och gödslingens inverkan.

$\mathrm{S}$ tråförkortningsmedlets inverkan på N/K förhållandet (Tabell 4). Granskar man resultaten för höstvetesorterna, förefaller talen för Vakka att vara mycket tillförlitliga och visar en liten stegring för CCC-användningen. För Virgo däremot är stegringen för stor och därigenom icke trovärdig, emedan proven togs för tidigt.

Bland vårvetesorterna är stegringen för CCC-användningen ungefär likadan för Svenno och Drott, men mycket obetydlig för Jo 04558. Att det inte blev någon stegring för Ring kan förklaras med att proven togs något för tidigt; enligt tidigare iakttagelser är Ring något senare än de andra sorterna. Förhållandet mellan sorterna Svenno och Drott överensstämmer också med Tabell 2.

För havresorterna har resultaten blivit mera otillförlitliga än för andra växtslag. Att det blivit en minskning i N/K förhållandet vid CCC-användningen för sorterna Linda och Hannes, torde bero på att proven tagits något för sent. För Risto och Sisu blev resultaten normala och överensstämmer med bladfärgen.

Av kornsorterna togs proven av 6-radiga Pomo för tidigt, varför talen blev för låga men visade dock stegring för CCC-användningen. På Paavo tycks CCC ha en särskilt stark inverkan, vilket även framgår av N/K förhållandet. Men det förefaller som om CCC inte skulle ha inverkat så mycket på strålängden hos Balder och Foma, måhända beroende på att denna är jämförelsevis kort, och detta har i sin tur gjort att det inte blivit någon stegring av N/K, utan att det t.o.m. hos Foma har blivit en minskning. Det är dock sannolikt, att detta inte skulle ha inträffat, om man varit mera noggrann med tiden för provtagningen. Förhållandet mellan N/K talen överensstämmer dock med dem från föregående år. Även för Karri kan en normal stegring vid CCC-användningen förmärkas. 
Tabell 4. Inverkan av CCC (4 kg/ha) på $\mathrm{N} / \mathrm{K}$ förhållandet.

Table 4. Effect of CCC (4 kg/ha) upon $\mathcal{N} / K$ proportion.

\begin{tabular}{|c|c|c|c|c|c|c|c|c|}
\hline $\begin{array}{l}\text { Art och sort } \\
\text { Species and variety }\end{array}$ & $\begin{array}{c}\text { CCC } \\
\text { använd } \\
\text { use }\end{array}$ & $\begin{array}{c}\text { Ax- eller } \\
\text { vippgång } \\
\text { Ear or panicle }\end{array}$ & $\begin{array}{l}\text { Provtagn. } \\
\text { datum } \\
\text { Sampling } \\
\text { date }\end{array}$ & & $\begin{array}{l}\text { lad- } \\
\text { ling* } \\
\text { leaf }\end{array}$ & $\begin{array}{l}\mathrm{N} \\
\%\end{array}$ & $\begin{array}{c}\mathbf{K} \\
\%\end{array}$ & $\mathrm{~N} / \mathrm{K}$ \\
\hline \multicolumn{9}{|c|}{ Höstvete - Winter wheat } \\
\hline Vakka & 0 & 24. 6.1971 & 3. 7.1971 & & 2.5 & 3.42 & 2.22 & 1.54 \\
\hline$"$ & CCC & $"$ & $"$ & & 2.6 & 3.80 & 2.40 & 1.58 \\
\hline Virgo & 0 & 28. 6.1971 & $"$ & & 3.5 & 3.05 & 2.10 & 1.45 \\
\hline$"$ & CCC & " & $n$ & & 3.6 & 3.11 & 1.63 & 1.91 \\
\hline \multicolumn{9}{|c|}{ Vårvete - Spring wheat } \\
\hline Svenno & 0 & 7. 7.1971 & 9. 7.1971 & 1 & 2 & 4.00 & 2.50 & 1.60 \\
\hline$"$ & CCC & $"$ & $"$ & 1 & 2.3 & 3.68 & 2.20 & 1.67 \\
\hline Drott & 0 & 5. 7.1971 & $n$ & & 4 & 3.95 & 2.24 & 1.76 \\
\hline " & CCC & $"$ & $"$ & & 4.2 & 4.00 & 2.00 & 2.00 \\
\hline Ring & 0 & 7. 7.1971 & $"$ & & 2 & 3.42 & 2.20 & 1.55 \\
\hline$m$ & CCC & " & $"$ & & 2.3 & 3.61 & 2.45 & 1.47 \\
\hline Jo 04558 & 0 & 6. 7.1971 & $"$ & $\mathrm{~m}$ & 1.5 & 3.19 & 2.25 & 1.42 \\
\hline$"$ & CCC & $n$ & $"$ & $\mathrm{~m}$ & 1.7 & 3.28 & 2.30 & 1.43 \\
\hline \multicolumn{9}{|l|}{ Havre - Oats } \\
\hline Linda & 0 & 7. 7.1971 & 12. 7.1971 & 1 & 3 & 3.04 & 2.80 & 1.09 \\
\hline " & CCC & $"$ & 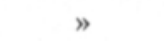 & 1 & 3 & 2.84 & 3.13 & 0.91 \\
\hline Risto & 0 & $"$ & $"$ & 1 & 3.5 & 2.55 & 3.47 & 0.74 \\
\hline$m$ & CCC & $"$ & $"$ & 1 & 4.2 & 3.72 & 2.97 & 1.25 \\
\hline Sisu & 0 & 6. 7.1971 & $"$ & 1 & 3.5 & 2.39 & 3.60 & 0.66 \\
\hline " & CCC & " & $n$ & 1 & 4 & 2.50 & 2.97 & 0.84 \\
\hline Hannes & 0 & 5. 7.1971 & $"$ & 1 & 3.5 & 3.93 & 3.25 & 1.21 \\
\hline$"$ & CCC & $"$ & $"$ & 1 & 3 & 3.50 & 3.92 & 0.89 \\
\hline \multicolumn{9}{|l|}{ Korn - Barley } \\
\hline Pomo, sexrad. & 0 & 10. 7.1971 & 16. 7.1971 & 1 & 2.5 & 2.11 & 2.92 & 0.72 \\
\hline$" \quad$ sixrow & CCC & " & $"$ & 1 & 3 & 2.03 & 2.45 & 0.83 \\
\hline Paavo, fyrrad. & 0 & 8. 7.1971 & 21. 7. 1971 & & 3 & 3.34 & 2.67 & 1.25 \\
\hline " fourrow & CCC & " & $n$ & & 4 & 2.53 & 1.67 & 1.51 \\
\hline Balder, tvårad. & 0 & 12. 7. 1971 & 24. 7. 1971 & & 2 & 3.04 & 2.55 & 1.19 \\
\hline$" \quad$ tworow & CCC & " & $n$ & & 2.2 & 2.92 & 2.45 & 1.19 \\
\hline Foma, tvårad. & 0 & $"$ & $"$ & & 4.2 & 3.06 & 2.15 & 1.42 \\
\hline$" \quad$ tworow & CCC & $" n$ & $"$ & & 4.3 & 3.23 & 2.60 & 1.24 \\
\hline Karri, tvårad. & 0 & 10. 7. 1971 & $n$ & & 3.2 & 3.01 & 2.35 & 1.28 \\
\hline$" \quad$ tworow & CCC & " & $n$ & & 3.5 & 3.20 & 2.30 & 1.39 \\
\hline
\end{tabular}

* Se Tabell 2.

* See Table 2. 
Vid en överblick av resultaten finner man, att man hos höst- och vårvetesorterna, för vilka man normalt brukar företaga besprutning med CCC, i allmänhet har erhållit en ökning av N/K förhållandet vid CCC-användningen, medan den hos havre- och kornsorterna har varit något osäkrare. Huvudorsaken till detta har varit, att då de har sluten blomning, har det varit svårt att iakttaga den rätta tidpunkten för provtagningen. I huvudsak har man dock även här fått fram, att CCC-användningen ökar N/K förhållandet.

För att man skall få ett säkert optimum för $\mathrm{N} / \mathrm{K}$ förhållandet för en sort, är dock ett års undersökningar otillräckliga, varför dessa måste fortsättas, varvid man kan undvika fel, som blivit begångna. Vidare bör beaktas, att förhållandet mellan blågrönt och gulgrönt hos bladen varierar något från år till år, så att den blågröna skiftningen framträder tydligare under varma och torra vårar och försomrar. Detta gör, att man bör taga bladprov för analysering under flera år för att erhålla ett tillförlitligt optimum för $\mathrm{N} / \mathrm{K}$ förhållandet hos de olika växtarterna och sorterna.

\section{Sammandrag}

Denna undersökning ingår i ett större sammanhang, nämligen frågan om torkresistensen och möjligheter att påvisa denna. Undersökningen har genom särskilda omständigheter lett fram till en metod att genom bladanalys erhålla ett förhållande mellan kväve och kalium, som är karakteristiskt för varje växtart och -sort. Detta $\mathrm{N} / \mathrm{K}$ förhållande är beroende av bladfärg, graderad efter skiftningen blågrön - gulgrön och mörk — ljus, vilken i sin tur beror på om klorofyll $\mathrm{a}$, blågrönt, eller klorofyll b, gulgrönt, dominerar och ger sin färg åt bladen. N/K förhållandet varierar från c:a 3.20 hos tallbarr och enens barr till c:a 1.00 hos vissa havresorter.

Vid analysering av prov från ett kombinerat bevattnings- och kvävegödslingsförsök $1964-67$ erhölls som resultat, att bevattningen genomgående höjer N/K liksom kvävegödslingen gör det.

Vid ett år 1971 anordnat försök med besprutning med stråförkortningsmedlet CCC ( $4 \mathrm{~kg} / \mathrm{ha})$ på ett antal höstvete-, vårvete-, havre- och kornsorter, visade det sig, att denna behandling, som vanligtvis åstadkommer en färgskiftning hos bladen i riktningen från gulgrönt till blågrönt, även i vanliga fall frambringar en höjning av N/K förhållandet.

\section{LITTERATUR}

Halldahl, P. 1966. Fotosyntesen. 119 p. Stockholm.

Lundegi̊rdh, H. 1954. Klima und Boden in ihrer Wirkung auf das Pflanzenleben. 598 p. Jena.

PưstJÄrvi, V. 1965. Neulasanalyysi männyn lannoitustarpeen ilmentäjänä. Metsätal. Aikakausl. $1: 1$-3. 